\title{
Model for interactive, collaborative and multimedia mobile learning environment
}

\author{
Danco Davcev \\ University Sts Cyril and Methodius \\ Faculty of Computer Science and Engineering \\ Karpos II, bb \\ +38923099155 \\ danco.davcev@finki.ukim.mk
}

\author{
Aleksandar Karadimce \\ University Sts Cyril and Methodius \\ Faculty of Computer Science and Engineering \\ Karpos II, bb \\ +38970300787 \\ akaradimce@ieee.org
}

\begin{abstract}
In this paper we propose a model for interactive, collaborative and creative multimedia distance learning in mCloud which goes beyond the existing solutions and provides personalized delivery of multimedia learning content. Our empirical results confirm that the larger groups of students and their usage of Web and mCloud lead to higher creativity of the students.
\end{abstract}

\section{Categories and Subject Descriptors}

K.3.1. [Computer and Education]: Computer Uses in Education - Collaborative learning.

\section{General Terms}

Experimentation.

\section{Keywords}

Multimedia collaborative creative learning, mCloud, Web.

\section{INTRODUCTION}

Mobile devices as service platforms for distance learning are being considered as excellent educational tools for sharing multimedia learning content between learners and teachers. Particular benefits of mobile learning systems are easy portability, real-time learning, autonomy, interaction and collaboration in the process of m-learning [1]. Existing mobile learning systems, which are based on traditional teaching and assessment principles, provide one and the same learning content to every student [2].

Certain progress can be observed with the introduction of the interactive mobile live video learning system in a cloud computing environment [3]. If the instructors' video presentation was captured in private cloud, the students can later progressively download or play the video by using the GPRS/WiFi connectivity on mobile device [3]. Another innovative technology for mobile devices is based on the Web 2.0 browsers, which allows teachers to author their own mobile learning environment and opens the opportunity for participation and collaboration anywhere, anytime [4]. The existing e-learning web sites and e-learning systems are providing excellent content, but they generally lack interactive response and face-to-face communication. There have been attempts to use web-based collaborative work and virtual interactive classrooms in order to inspire creativity in e-learning

Permission to make digital or hard copies of all or part of this work for personal or classroom use is granted without fee provided that copies are not made or distributed for profit or commercial advantage and that copies bear this notice and the full citation on the first page. To copy otherwise, or republish, to post on servers or to redistribute to lists, requires prior specific permission and/or a fee.

MoMM2013, 2-4 December, 2013, Vienna, Austria.

Copyright 2013 ACM 978-1-4503-2106-8/13/12 ...\$15.00.
[5]. Findings in [6] show that online social networking, foster multi-disciplinary collaborations by providing a platform for researchers from diverse backgrounds to find one another and cooperate on issues of common interests. The proposed learning environment in [7] provides a motivating and innovative studentcentric platform for performing laboratory experiments by using a type of monitoring system via simulation. It not only conveys knowledge and skills to students but also develops their creativity, collaboration and personality. In our approach, we provide a system with a high interaction, social group collaboration (for increased attention of self-created groups of students) and group creativity among the students by using the advantages of the mobile Cloud (mCloud). The instructor is just an organizer and advisor on the group level, while the students, supported by the Web, are searching the learning multimedia content in high interactive, collaborative and creative way.

This paper is organized as follows: Section 2 presents the related work. In Section 3 we present a general framework of the model for such a system, while our empirical results for the graduate students in Computer science and engineering at our University are given in the Section 4 . The last Section 5 concludes the paper and gives our future research directions.

\section{RELATED WORK}

It is generally accepted in the field of creativity that thought is divided into both convergent and divergent processes. There are several existing models for how these general processes of divergent and convergent thought manifest in practice $[9,10,11$, $12,13]$.

Divergent processes are those typically associated with creativity and entail looking at a solution in multiple frames rather than in a single, rigid context. As its name suggests, divergent thinking involves generating vast numbers of disparate ideas. However, creative solutions have been described in cognitive psychology as those that are both original and relevant. Convergent thinking deals with the latter by analyzing ideas for relevancy and feasibility, discarding anything impractical.

Creative conversation not only occurs between an individual and his or her own work, but also through collaboration and relationships between an individual and other human beings [9]. Working in groups allows individuals an opportunity to manage difficult problems by breaking them down into sub problems. Collaboration also allows team members to produce more ideas, share different perspectives and re-interpret each other's ideas [8].

It is important to have tools that support brainstorming sessions, like many group support systems (GSS). However, our work is trying to take a broader perspective and processes in team design practice as they occur over a longer period of time. 
Groupware is defined as multi-user software that is designed to help team members coordinate and track joint projects [14]. According to [8] groupware tools do little to improve the creativity of group ideas except the speed at which ideas are communicated. These tools should focus on the creation/ manipulation of cognitive externalizations (visual expressions as a means to externalize the thoughts and ideas of team members through unique representations) and awareness tools in order to both maximize the use of group creative resources and minimize barriers that exist for groups in general.

Literature, to date, suggests that groupware specifically aimed at augmenting group creativity should focus on the creation/manipulation of externalizations and awareness tools in order to both maximize the use of group creative resources and minimize barriers that exist for groups in general. Much of the work done is conceptual and provides directions to pursue [9]. In [16], Zhiwen have used fuzzy logic theory and dynamic QoS mapping to determine the appropriate presentation according to the user's QoS requirements and device/network capability. Some of the proposed media deliverer systems are supporting wide variety of video, audio, and image formats and can adapt to different terminals and network conditions [16].

\section{GENERAL FRAMEWORK OF THE MODEL}

The main advantages of the cloud computing in general are: centralized storage, memory and data processing providing increased capacity for multimedia distribution.

The proposed framework for our model for interactive, collaborative and creative multimedia distance learning in mCloud (Figure1) goes beyond the existing solutions and provides interactive, collaborative and creative delivery of multimedia learning content.

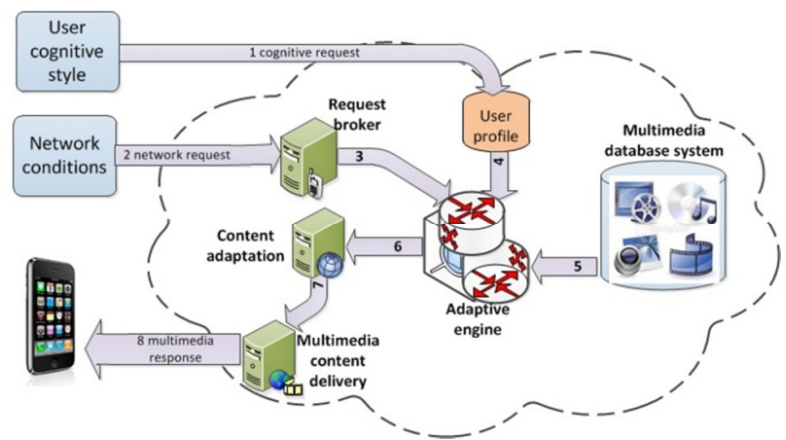

Figure 1. Framework of the interactive, collaborative and creative Web and mCloud learning environment.

Our model, as can be seen from Figure 1 initially uses the student's feedback interaction received form the collaborative social learning tools for collecting user cognitive style estimation. In order to prepare adapted learning material for the student, in the same time, we consider the context-aware network conditions that have significant influence during delivery of large-scale multimedia content in the mCloud. All of the requests from user's mobile device and heavy-duty processing tasks will be executed in the mCloud and the response is appropriate multimedia content. The main role of mobile cloud computing is to offload and to reduce the workload of mobile devices by exploiting the remote multimedia processing resources in the mCloud.
Considering the different cognitive style dimension of the user the mCloud receives (1) users cognitive request, which is stored in user profiles database. The request broker (3) role is to gather the context-aware information, network conditions (2), from the mobile user. Next, content adaptive engine is analyzing the different requests from the request broker (3) and user profiles database (4) and prepares the multimedia content from the multimedia database (5) to be adapted to the context-aware conditions and user cognitive style. The adopted algorithm for multimedia adaptation is sent to the content adaptation component (6) to adapt the multimedia content. After content adaptation estimation (7) is done the multimedia content delivery component is sending multimedia response to the mobile device (8).

Initially, after the creation of the groups of students by themselves (for increased attention), the instructor is responsible for set-up the learning topics on the group level with some basic content and some introductory suggestions. After this initial step, the instructor is just an organizer and advisor on the group level. Then, the students are searching the learning multimedia content in high interactive collaborative and creative way. The students communicate via Web in different ways: forum, chatting, exchange of messages and content etc.

\section{THE ADAPTATION ALGORITHM FRAMEWORK}

We are proposing an algorithm for multimedia content adaptation in the mCloud, which considers user preference profile, network characteristics and client device capabilities. It is similar in spirit with the algorithm presented in [15]. For simplicity we assume that there is no correlation between these three influencing dimensions. Since an adaptation process can be carried out in a number of adaptation steps and there could be several adaptation services which execute each adaptation task that leads to different service composition possibilities.

The service for user's cognitive style can differentiate between verbalizers and visualizers, which provides the decision on the type of multimedia content. Usually, client receives both: text or audio; and images or video seamlessly, but with different ratio aspect that we associate a weight factor $0<\mathrm{w}<1$. Considering the above the user's cognitive style service $S_{c}$ is defined as in (1).

$$
S_{c}=w_{v i s} * q_{v i s}+w_{v e r} * q_{v e r}
$$

Where $\mathrm{q}$ is the relationship associated with the given type of multimedia content.

Next step in the adaptation process is the context-aware network service that has significant influence during delivery of multimedia content. We have identified the limited network bandwidth as influencing QoS factor presented by the $\mathrm{q}$ in equation (2).

$$
S_{n}=w_{b a n} * q_{b a n}
$$

Different mobile device types have certain dissimilarities that should be considered, such as screen dimension, encoding modes, memory buffer size etc. We have identified the screen size and encoding as major influencing factors that affect the client's mobile device capabilities, as presented in (3).

$$
S_{d}=w_{e n c} * q_{e n c}+w_{s i z} * q_{s i z}
$$


Adaptation engine computes the aggregate score for a given adaptation services transformations services that should be done, represented in (4) by $A(S)$.

$$
A(S)=S_{c}+S_{n}+S_{d}
$$

Equation (4) defines the complete adaptation service selection path that should be completed in order to get the desired multimedia content delivered to the client.

\section{EMPIRICAL RESULTS}

Here we present the results for the postgraduate students in Computer Science and Engineering for the course in Management Information Systems (MIS). As can be seen from Table 1, in 2010 and 2011 only one student in a group was using Web or mCloud as a support for his/her work resulting in only one published paper. In 2012, two students out of five in the group used Web and/or mCloud resulting in three published papers and one under review. Finally, in 2013 three out of six students in the group were supported by Web and/or mCloud for communication and searching of additional documents resulting in three published papers and additional three under review (one paper is still under preparation).

We can conclude that as the number of students using the Web and/or mCloud for searching and communication increases in the groups, the number of research papers as a result of their work increases as well. For 2013, 50\% of the students per group have used Web and/or mCloud for communication and content search resulting in increased number of three already accepted papers and additional three under review. The work of students in mCloud environment influences their creativity as well.

Table 1. Empirical results for the student in MIS

\begin{tabular}{|c|c|c|c|c|}
\hline $\begin{array}{c}\text { YEAR } \\
\text { (MIS-II } \\
\text { Cycle) }\end{array}$ & $\begin{array}{c}\text { No. } \\
\text { of } \\
\text { stud } \\
\text { ents }\end{array}$ & $\begin{array}{c}\text { No. } \\
\text { of } \\
\text { gro } \\
\text { ups- } \\
\text { proj } \\
\text { ects }\end{array}$ & $\begin{array}{c}\text { Average no. } \\
\text { of students } \\
\text { per } \\
\text { group/No. of } \\
\text { students } \\
\text { using } \\
\text { Web/CI }\end{array}$ & $\begin{array}{c}\text { No. of } \\
\text { research } \\
\text { papers }\end{array}$ \\
\hline 2010 & 30 & 10 & $3 / 1$ & 1 \\
\hline 2011 & 32 & 8 & $4 / 1$ & 1 \\
\hline 2012 & 31 & 6 & $5 / 2$ & 3 \\
\hline 2013 & 30 & 5 & $6 / 3$ & $3+3$ \\
\hline
\end{tabular}

We can see from the Table 1 that the potential number of papers is increased as a result of increased possibilities for exchange of ideas among the students and teachers within the mCloud.

\section{CONCLUSION AND FUTURE WORK}

In this paper we have proposed a framework for a model of interactive, collaborative and creative mCloud learning environment. The instructor is just an organizer and advisor on the group level, while the students, by using the Web, are searching the learning multimedia content in high interactive, collaborative and creative way.

We are also developing an algorithm for intelligent multimedia content adaptation and creation. In this paper, only a framework of the algorithm is presented. This algorithm, tools and services, will provide sharing of creative experience, continuous evaluation and increased collaboration among learners and teachers.

The empirical results created by analysis and surveys of the graduate students in Computer science and engineering at our University show that the larger groups and the usage of Web and mCloud for searching the content and communication among the students leads to higher creativity of the student' groups.

In our future work, we plan to provide an extensive analysis of the attention process within the groups created by the student themselves. We expect an increased quality of creative learning compared to traditional non student centric learning. The increased attention and creative process within the group (supported by the usage of Web and mCloud for content retrieval and communication) should be the crucial factor for this increased efficiency of learning and it will be proved on the basis of the surveys and Quality of Experience (QoE) metrics developed at our Department.

\section{REFERENCES}

[1] Chen, S., Lin, M., and Zhang, H. 2011. Research of mobile learning system based on cloud computing. In Proceedings of the International Conference on e-Education, Entertainment and e-Management ICEEE, 27-29 Dec. 2011. ISBN: 978-14577-1381-1, 121-123.

[2] Hirsch, B. and Ng, J. W.P. 2011. Education Beyond the Cloud: Anytime-anywhere learning in a smart campus environment. In Proceedings of the 6th International Conference of Internet Technology and Secured Transactions, 11-14 Dec. 2011, Abu Dhabi, Unated Arab Emirates. ISBN: 9781457708848., 718-723.

[3] Mohana Saranya, S. and Vijayalakshmi, M. 2011. Interactive mobile live video learning system in cloud environment. In Proceedings of the IEEE International Conference on Recent Trends in Information Technology, ICRTIT 2011. 3-5 Jun. 2011. Chennai. DOI: 10.1109/ICRTIT.2011.5972458., 673677.

[4] Bai, X. 2010. Affordance of Ubiquitous Learning through Cloud Computing. In Proceedings of the Fifth International Conference on Frontier of Computer Science and Technology, 978-0-7695-4139-6/10, 2010 IEEE DOI: 10.1109/FCST.2010.109., 78-82.

[5] Premchaiswadi, W., Tungkasthan, A., and Jongsawat N. 2010. Enhancing Learning Systems by using Virtual Interactive Classrooms and Web-based Collaborative Work. In Proceedings of IEEE EDUCON Education Engineering 2010- The Future of Global Learning Engineering Education. 14-16 April 2010, Madrid, Spain.,1532-1537.

[6] Jung Sun, O. and Wei, J. 2011. Groups in Academic Social Networking Services--An Exploration of Their Potential as a Platform for Multi-disciplinary Collaboration. In Proceedings of IEEE third international conference on social computing (socialcom), 9-11 Oct. 2011, 545-548.

[7] Xuemei, L., Yan, and Ding Lixing, L. 2009. Study on Student-oriented Education based on MCGS in Engineering Courses. In Proceedings of IEEE ISECS International Colloquium on Computing, Communication, Control, and Management, 454-456.

[8] Venkataswamy, A., Sodhi, R., Abdildin Y., and Bailey, B.P. 2009. Groupware for Design: an Interactive System to Facilitate Creative Processes in Team Design Work. In 
Proceedings of the 42nd Hawaii International Conference on System Sciences.

[9] Amabile, T. M. 1983. The Social Psychology of Creativity: A Componential Conceptualization. In Journal of Personality and Social Psychology 45, no. 2 (August 1983): 357-377.

[10] Cross, N. 2002. Creative Cognition in Design: Processes of Exceptional Designers. In Proceedings of the ACM Conference on Creativity \& Cognition, ACM Press, New York (2002), 14-19.

[11] Gabora, L. 2002. Cognitive mechanisms underlying the creative process. In (T. Hewett and T. Kavanagh, Eds.) Proceedings of the Fourth International Conference on Creativity and Cognition, October 13-16, Loughborough University, UK, 126-133.

[12] Moran, T. and Carroll, J. 1996. Design Rationale: Concepts, Techniques, and Use. In Lawrence Erlbaum Associates, Inc., Hillsdale,NJ

[13] Paulus, P.B. and. Yang, H.C. 2000. Idea generation in groups: A basis for creativity in organizations. In Organizational Behavior and Human Decision Processes, Vol 82, Issue 1, 76-87.

[14] Yardi, S., Hill B., and Chan, S. 2005. VERN: facilitating democratic group decision making online. In Proceedings of the 2005 international ACM SIGGROUP conference on Supporting group work (GROUP '05). ACM, New York, NY, USA, 116-119. DOI=10.1145/1099203.1099223 http://doi.acm.org/10.1145/1099203.1099223

[15] Fudzee, M. F. M. Abawajy, J., and Deris, M. M. 2010. Multicriteria Content Adaptation Service Selection Broker. In Proceedings of the 2010 10th IEEE/ACM International Conference on Cluster, Cloud and Grid Computing (CCGRID '10). IEEE Computer Society, Washington, DC, USA, 721-726. DOI=10.1109/CCGRID.2010.128 http://dx.doi.org/10.1109/CCGRID.2010.128

[16] Yu, Z., Nakamura, Y., Zhang, D., Kajita, S., and Mase, K. 2008. Content Provisioning for Ubiquitous Learning. IEEE Pervasive Computing 7, 4 (October 2008), 62-70. DOI=10.1109/MPRV.2008.69 http://dx.doi.org/10.1109/MPRV.2008.69

[17] Yu, Z., Zhou, X., Zhang, D., Chin, C.Y., Wang, X., and Men, J. 2006. Supporting Context-Aware Media Recommendations for Smart Phones. IEEE Pervasive Computing 5, 3 (July 2006), 68-75. DOI=10.1109/MPRV.2006.61 http://dx.doi.org/10.1109/MPRV.2006.61 